\title{
Silymarin, A Promising Nature's Remedy for Liver Diseases
}

\author{
Ruchi Mitra ${ }^{1 *}$ and Mitra JK \\ ${ }^{1}$ Department of Dentistry, Rajendra Institute of Medical Sciences, India \\ ${ }^{2}$ Department of Medicine, Rajendra Institute of Medical Sciences, India
}

Submission: March 20, 2017; Published: August 21, 2018

*Corresponding author: Ruchi Mitra, Department of Dentistry, Rajendra Institute of Medical Sciences, Ranchi, Jharkhand, India, Tel: +918678000300; Email : drruchimitra@gmail.com

\begin{abstract}
Chronic liver diseases remains as one of the most serious health problems worldwide. Chronic liver disease involves a wide range of liver pathologies that include fatty liver, hepatitis, fibrosis, cirrhosis,and hepatocellular carcinoma. Since ancient times herbal medicines have been used for various diseases. In the recent decades an increasing number of herbal products, including medicinal herbs and phytochemicals, have been used for treating a variety of diseases worldwide. Thereby, numerous medicinal herbs and phytochemicals have been used as complementary and alternative treatments for chronic liver diseases. Thus, the present review explores the current knowledge of the herbal medicine silymarin in treating chronic liver diseases and on its flaws which need to be overcome in future studies.
\end{abstract}

Keywords: Liver; Cirrhosis; Silymarin; Hepatocellular carcinoma; herbal medicines; Hepatitis

\section{Introduction}

The various forms of chronic liver diseases are most widely spread which include viral hepatitis, alcoholic or nonalcoholic fatty liver disease, autoimmune hepatitis, cirrhosis and hepatocellular carcinoma [1]. Although there have been a remarkable progress in discovering treatment of chronic liver diseases over the last several decades, most of the therapies are still unsatisfactory [2].

According to the earlier studies, medicinal herbs and phytochemicals could protect the liver by several mechanisms such as eliminating virus, blocking fibrogenesis, inhibiting oxidative injury and suppressing tumorigenesis [3,4]. Liver diseases are generally chronic disease, most liver injuries need long-term treatment, thus, reducing side-effects of the therapy is critical when developing novel hepatoprotective agents. Most of the patients believe that medicinal herbs and phytochemicals are natural and safe to be administrated without significant toxicity or side effects but all medicinal agents including herbal medicines potentially have toxicity and side effects which needs to be ruled out. For safe use of medicinal herbs and phytochemicals, the potential side effects and toxicity of the herbal medicines should be seriously taken into consideration [4].

Milk thistle (Silybum marianum) has been used since ancient times as a liver tonic. The extracts of the flowers and leaves of Silybum marianum have been used for centuries to treat liver, spleen and gallbladder disorders [5]. In the 1960s the biologically active principles of the seed and fruit extracts were studied, and the chemical structures were obtained. Sonnenbichler et al [6] isolated a mixture named silymarin, and it was with flavonolignan mixture that most clinical studies were carried out. Another historical reference was found in the Bible, in which the plant is also called "Lebanon cardus". A better description of its characteristics dates back to the Pliny the Elder age (23-79 A.D.) in which its juice and seeds were used as remedy in case of poisoning due to snake bite and in melancholic depression, a pathology that was supposed to be associated with "liver complaint" [7]. The English herbalist and physician Nicolas Culpepper (1616-1654) noted that milk thistle can be used to open the obstructions of the liver and spleen, and thereby is good against the jaundice, and its use in liver disease was also documented by the Swiss physician Albrecht von Haller (1708-1777) [8]. After the Middle Ages, the use of Silybum marianum in medicine has increased even more, and, at the same time, scientific data derived from its use has been included in liver pathologies [7].

This review explores the pharmacology, mode of action, efficacy and safety of silymarin compounds in chronic liver diseases to assess the efficacy of traditional medicines over allopathic medications.

\section{Silymarin}

Silymarin is obtained from silybum marianum (milk thistle), an edible plant that has been used medicinally for centuries as a herbal medicine for the treatment of liver related disorders. 
The plant is native to the Mediterranean andis widely found in Europe and North America [9]. It also grows in India, China, South America and Australia. This herb is approved for sale in Canada in different products and gains an annual business of 180 million in Germany [1].

Silymarin is a polyphenolic flavonoid, extracted using 95\% ethanol, from the seeds of the milk thistle. The plant consists of approximately $70-80 \%$ of silymarin flavonolignans and approximately $20-30 \%$ undefined fraction. The most prevalent component is Silybin (50-60\% of Silymarin). It consists of seven flavonoglignans (silibinin, isosilibinin, silychristin, isosilychristin and silydianin) and a flavonoid (taxifolin) [10].

\section{Pharmakokinetics}

Silymarin is insoluble in water and is often administered in a capsulated form $[1,11]$. It is absorbed orally, with peak plasma concentration in 6-8 hr. But, the oral absorption of silymarin is only about $23-47 \%$ leading to low bioavailability. The poor water solubility and bioavailability led to the development of enhanced formulations like silipide (Siliphos) a complex of silymarin and phosphatidylcholine which is ten times more bioavailable.

\section{Mechanism of action}

Silymarin's hepatoprotective effects are accomplished by several mechanisms which include antioxidant, inhibition of lipid peroxidation, enhanced hepatocyte regeneration, enhanced liver detoxification and protection from glutathione depletion, antiinlammatory effects including inhibition of leukotriene, prostaglandin synthesis and kupffer cells, mast cell stabilization. slowing of fibrosis by reducing conversion of hepatic stellate cells.

\section{Adverse Effects}

Silymarin has very low toxicity and has been shown a good safety profile. At high doses it has a laxative effect due to increased bile secretion, adverse effects related to GI tract were reported in $2-10 \%$ patients in a clinical trial [12].

\section{Literature Review}

Velussi et al. [13] conducted a trial in 60 cirrhotic diabetic. Patients were randomly assigned to receive silymarin $600 \mathrm{mg} /$ day or no silymarin for 12 months, with both the groups receiving standard therapy. The baseline features were similar in both the groups. Silymarin treatment produced a significant reduction in daily and fasting blood glucose, daily glucosuria, glycosylated haemoglobin values, malondialdehyde values and a drop in insulin requirement and fasting insulinaemia. In contrast, the status of untreated patients declined during the trial. The authors concluded that silymarin may reduce the lipoperoxidation of cell membrane and insulin resistance, by significantly decreasing endogenous insulin overproduction and the need for exogenous insulin administration. Silymarin is reported to have a very good safety profile 5 . Both animal and human studies showed that silymarin is non toxic even when given at high doses (>1500 mg/ day). However, a laxative effect is noted at these doses may be due to increased bile secretionand bile flow [14].

A randomized double blind multicenter study was conducted to study the effect of silymarin in alcoholics with liver cirrhosis with respect to their survival, clinical and laboratory changes [15]. comparing $450 \mathrm{mg} /$ day in three divided doses $(\mathrm{n}=103)$ with placebo ( $\mathrm{n}=97)$, enrolled 200 alcoholics with histologically or laparoscopically proven liver cirrhosis. They concluded that the survival was similar in patients receiving silymarin or placebo and was not influenced by the gender, the persistence of alcohol intake, the severity of liver dysfunction or by the presence of alcoholic hepatitis in the liver biopsy.

\section{Conclusion}

Silymarin is a nature's essence which is now widely being used for liver cirrhosis, hepatitis other diseases like mushroom poisoning, cancer therapy, antiageing, cardiopulmonary problems and various skin disorders. The excellent hepatoprotective properties of silymarin besides its immunomodulatory, antioxidant and anti-inflammatory activities as evident from previous literature makes it a promising drug of today. However, further studies related to the possible synergistic activity or be it the therapeutic activity need to be carefully ruled out for establishing the remedial efficacy of the herbal product.

\section{References}

1. Vong S, Bell BP (2004) Chronic liver disease mortality in the united states, 1990-1998. Hepatology 39(2): 476-483.

2. Wang BE (2000) Treatment of chronic liver diseases with traditional chinese medicine. J Gastroenterol. Hepatol 15: E67-E70.

3. Dhiman A, Nanda A, Ahmad S (2012) A recent update in research on the antihepatotoxic potential of medicinal plants. J Chin Integr Med 10(2): 117-127.

4. Del Prete A, Scalera A, Iadevaia MD, Miranda A, Zulli C (2012) Herbal products: Benefits, limits, and applications in chronic liver disease. Evid Based Complement. Altern Med, pp.19.

5. Rainone F (2005) Milk thistle. Am Family Phys 72(7): 1285-1288.

6. Sonnenbichler J, Scalera F, Sonnenbichler I (1999) Stimulatory effects of silibinin and silicristin from the milk thistle Silybum marianum on kidney cells. J Pharmacol Exp Ther 290(3): 1375-1383.

7. Schadewaldt H (1969) The history of Silymarin. Contribution to the history of liver therapy. Die Med. Welt 20(15): 902-914.

8. Der Marderosian A (2003) Milk Thistle. Review of Natural Products. Fact and Comparisons. St Louis, MO: Facts and Comparisons Publishers.

9. Luper S (1998) A review of plants used in the treatment of liver disease. Part 1. Altern Med Rev 3(6): 410-421.

10. Kim NC, Graf TN, Sparacino CM, Wani MC, Wall ME (2003) Complete isolation and characterization of silybins and isosilybins from milk thistle (Silybum marianum). Org Biomol Chem 1(10): 1684-1689.

11. Kidd P, Head K (2005) A review of the bioavailability and clinical efficacy of milk thistle phytosome: A silybin- phosphatidyl complex. Altern Med Rev 10(3): 193-203.

12. Bosisio E, Benelli C, Pirola O (1992) Effect of the favanolignans of Silybum marianum $\mathrm{L}$ on lipid peroxidation in rat liver microsomes and freshly isolated hepatocytes. Pharmacol Res 25(2): 147-154. 
13. Velussi M, Cernigoi AM, De Monte A, Dapas F, Caffau C,Zilli M (1997) Long-term (12 months) treatment with an anti-oxidant drug (silymarin) is effective on hyperinsulinemia, exogenous insulin need and malondialdehyde levels incirrhotic diabetic patients. J Hepatol 26(4): 871-879.

This work is licensed under Creative Commons Attribution 4.0 License

DOI: 10.19080/JCMAH.2018.07.555704
14. (1999) Silybum marianum (Milk thistle). Alt Med Rev 4(4): 272-4.66.

15. Pares A, Planas R, Torres M, Caballera J, Viver JM, et al (1998) Effects of silymarin in alcoholic patientswith cirrhosis of liver: results of a controlled double-blind randomized and multicenter trial. J Hepatol 28(4): 615-21.

\section{Your next submission with Juniper Publishers will reach you the below assets}

- Quality Editorial service

- Swift Peer Review

- Reprints availability

- E-prints Service

- Manuscript Podcast for convenient understanding

- Global attainment for your research

- Manuscript accessibility in different formats

( Pdf, E-pub, Full Text, Audio)

- Unceasing customer service

Track the below URL for one-step submission https://juniperpublishers.com/online-submission.php 